\title{
Estimate of Mixed Convection Heat Transfer and Fluid Flow Characteristics of Plate-fin Heat Sinks in the Opening of the Enclosure
}

\author{
Han-Taw Chen", Chung-Yi Wu \\ Department of Mechanical Engineering, National Cheng Kung University, Taiwan
}

Copyright $\bigcirc 2016$ by authors, all rights reserved. Authors agree that this article remains permanently open access under the terms of the Creative Commons Attribution License 4.0 international License.

\begin{abstract}
This study uses an inverse method and commercial package FLUENT along with the experimental data to obtain heat transfer and fluid flow characteristics of plate-fin heat sinks placed in a rectangular enclosure with two openings. A cooling fan placed on the top of the fins is blown downward. Another fan is placed on the outside of the opening in order to extract the air inside the enclosure. The inverse method along with the experimental temperature data is applied to estimate the heat transfer coefficient on the fins. Afterward, a commercial package FLUENT along with the zero-equation turbulence model, experimental temperature data and the resulting heat transfer coefficient is used to obtain heat transfer and fluid flow characteristics of plate-fin heat sinks within a rectangular enclosure with openings. The resulting heat transfer coefficient and fin temperature at the selected measurement locations are close to inverse results and the experimental temperature data, respectively. Thus, the zero-equation turbulence model is suitable for this problem.
\end{abstract}

Keywords Inverse Method, FLUENT, Experimental Data, Heat Sinks, Enclosure with Openings

\section{Introduction}

Natural convection heat transfer with heat sink and extended surfaces has been widely used in engineering applications. In recent years, with the rapid development of electronic technology, promoting the heat transfer rate under the working process at the desired operating temperature may play an important role to ensure reliable operation of the electronic components. The appropriate design of the heat sink has gradually become attractive for these applications because they provide a more economical solution to the above problem.

Conventional electronic cooling normally used the heat sink with the cooling fan to show the superiority in terms of unit price, weight and reliability. In order to design a practical heat sink, some criterions such as a large heat transfer rate, a low pressure drop, and a simpler structure should be considered. The fins in the heat sink are always applied to increase the heat flow per unit of basic surface. However, it is necessary to note the interactions between the local heat transfer and flow distribution between two fins in designing the heat sink. It is known that most of previous works about the effect of the fin spacing in the heat sink are limited to the experiment or the numerical analysis. From Ref. [1], the measurement of the local heat transfer coefficient on the plate fin under steady-state heat transfer conditions may be very difficult to perform because the local fin temperature and local heat flux must be required. Thus, reliability can be an important concept in engineering design. The use of reliable components enables the designers to utilize more sophisticated techniques to improve the performance of the heat sinks [2]. Thus the estimation of a more accurate heat transfer coefficient on the fin may be an important task for the device of the high-performance heat sinks.

The experimental and numerical studies for the heat transfer from an array of parallel rectangular finned surfaces on a horizontal surface have been studied for a long time. Such problems may exhibit the complex three-dimensional flow and thermal fields for a wider range of fin geometry. Although, most of the existing studies provide valuable results for this problem, the results are still inconclusive, especially for the comparative experimental results. In other words, the available experimental data can remain very limited. Thus, a more accurate predictive scheme based on experimental data can be required to obtain the reliable heat transfer characteristics for plate-fin heat sink (PFHS).

Numerical studies and some experiments for thermal performances of the plate-fin and plate-pin-fin heat sinks have been investigated by $\mathrm{Yu}$ et al. [3], Kim et al. [4] and Li and Chao [5]. The thermal resistance of the heat sink is 
obtained from the ratio of the temperature difference between the highest fin base temperature and the ambient air temperature to the heat dissipation power applied on the fin base. El-Sayed et al. [6] varied the fin height, fin width, fin spacing, number of fins and the distance from the fin tip to the shroud to study the performance of a PFHS. El-Sayed et al. [6] concluded that the pressure drop decreased with increasing the fin spacing. The mean Nusselt number increases with fin spacing. Under the assumptions of the one-dimensional heat conduction model and the constant mean heat transfer coefficient, El-Sayed et al. [6] proposed the relation between the average Nusselt number and Reynolds number. The results show that the optimum geometric parameters of the fin thickness and fin spacing respectively are $0.8 \mathrm{~mm}$ and $2.0 \mathrm{~mm}$ in the PFHS.

It is known that the heat transfer characteristics between the two fins are closely related with the airflow patterns. Velayati and Yaghoubi [7] applied the finite volume method along with the SIMPLE pressure-velocity coupling algorithm to solve three-dimensional turbulent flow and heat transfer characteristics of parallel heated rectangular plates mounted over an insulating base plate. From Ref. [7], three-dimensional complex flow characteristics within parallel bluff plates can be observed. This complex flow pattern is accompanied by fluid separation and reattachment. Sparrow et al. [8] used experimental investigation to study heat transfer and pressure drop for airflow in arrays of heat generating rectangular modules deployed along one wall of a flat rectangular duct. Elshafei [9] applied theoretical and experimental studies to investigate the effects of the duct speed, fin density and tip-to-shroud clearance on flow bypass, thermal performance and pressure drop across a longitudinal aluminum fin array.

Chen et al. [10] used inverse method along with the finite difference method, the experimental temperature data and least squares method to predict the natural convection heat transfer coefficient on the fins mounted on a horizontal heated plate for various values of the fin spacing and fin height. The resulting heat transfer coefficient based on the fin base temperature is in good agreement with that obtained by the correlation [11]. This means that the inverse method proposed by Chen et al. [10] has good accuracy. Thus, this study uses the inverse method [10] and FLUENT [12] along with experimental data to determine the mixed convection heat transfer and fluid flow characteristics for various values of the fin spacing. The inverse method along with the experimental temperature data is first applied to estimate the heat transfer coefficient on the fins. In order to determine more reliable numerical results, the resulting heat transfer coefficient and fin temperatures at the selected measurement locations are compared with inverse results and experimental temperature data, respectively.

\section{Inverse Method}

The two-dimensional inverse heat conduction problem is introduced to estimate the unknown heat transfer coefficient on the fin of the plate-fin heat sink for various fin heights. Fin temperature measured at the selected locations and the ambient air temperature are measured by the experimental apparatus constructed in a rectangular enclosure with two openings, as shown in Fig. 1. It is seen from Fig. 1 that a cooling fan placed on the top of the fins is blown downward. Another fan is placed on the outside of the opening in order to extract the air inside the enclosure. The bottom side of the enclosure has a small opening to draw in cool air. The inverse method proposed by Chen et al. [10] along with the experimental temperature data is used to predict the heat transfer coefficient on the vertical fins mounted on a horizontal heated plate. Due to the assumption of non-uniform distribution of heat transfer coefficient, the entire fin is divided into several sub-fin regions. The heat transfer coefficient in each sub-fin region is assumed to be an unknown constant. The measurement locations and sub-fin regions is shown in Fig. 2. Under the assumption of the thin fin, the temperature gradient in the z-direction (the fin thickness) is neglected. The boundary conditions at the edge surface of the fins may be assumed to be insulated [10]. Under the assumption of steady state and constant thermal properties, the heat conduction equation for a thin fin can be expressed as

$$
\frac{\partial^{2} T}{\partial x^{2}}+\frac{\partial^{2} T}{\partial y^{2}}=\frac{2 h(x, y)}{k_{f} t}\left(T-T_{c}\right) \text { for } 0<\mathrm{x}<\mathrm{L}, 0<\mathrm{y}<\mathrm{H}
$$

The corresponding boundary conditions are

$$
\begin{gathered}
\frac{\partial T}{\partial x}=0 \quad \text { at } \quad \mathrm{x}=0 \text { and } \mathrm{x}=\mathrm{L} \\
\mathrm{T}(\mathrm{x}, 0)=\mathrm{T}_{0} \quad \text { at } \mathrm{y}=0
\end{gathered}
$$

and

$$
\frac{\partial T}{\partial y}=O \quad \text { at } \quad \mathrm{y}=\mathrm{H}
$$

where $\mathrm{T}$ denotes the fin temperature. $\mathrm{x}$ and $\mathrm{y}$ are the Cartesian coordinates. $\mathrm{L}, \mathrm{H}$ and $\mathrm{t}$ denote the length, height and thickness of the fins, respectively. $h(x, y)$ is the unknown heat transfer coefficient. $\mathrm{k}_{\mathrm{f}}$ is the thermal conductivity of the fin. $T_{0}$ and $T_{\infty}$ are the fin base temperature and ambient air temperature, respectively.

The application of the finite difference method to Eq. (1) can produce the difference equation in the $k$ th sub-fin region as

$$
\begin{array}{r}
\frac{T_{i+1, j}-2 T_{i, j}+T_{i-1, j}}{\ell_{x}^{2}}+\frac{T_{i, j+1}-2 T_{i, j}+T_{i, j-1}}{\ell_{y}^{2}}=\frac{2 \bar{h}_{k}}{k_{f} t} T_{i, j} \text { for } i \\
2, \ldots, N_{x}, j=1,2, \ldots, N_{y}, k=1,2, \ldots, N
\end{array}
$$

where $\mathrm{N}_{\mathrm{x}}$ and $\mathrm{N}_{\mathrm{y}}$ are, respectively, the number of nodes in the $\mathrm{x}$ - and $\mathrm{y}$-directions. $\ell_{\mathrm{x}}$ and $\ell_{\mathrm{y}}$ are defined as $\ell_{\mathrm{x}}=\mathrm{L} /\left(\mathrm{N}_{\mathrm{x}}-1\right)$ and $\ell_{\mathrm{y}}=\mathrm{L} /\left(\mathrm{N}_{\mathrm{y}}-1\right)$. $\mathrm{N}$ is the number of sub-fin region.

The difference equation for the node at the boundary surface and the interface of two adjacent sub-fin regions is 
similar to that shown in Ref. [10]. To avoid repetition, a detailed procedure can be found in Ref. [10]. Rearrangement of these difference equations and Eq. (5) yields the following matrix equation.

$$
[\mathrm{K}][\mathrm{T}]=[\mathrm{F}]
$$

where $[\mathrm{K}]$ is the global conduction matrix. $[\mathrm{T}]$ is the matrix representing the nodal temperatures. $[\mathrm{F}]$ is the force matrix. The fin temperature at the selected measurement locations can be obtained from Eq. (6) using Gauss elimination.

T-type thermocouple is used to measure the fin temperature only at selected locations. The least-squares method is used to minimize the sum of the squares of the deviations between the calculated and measured fin temperatures at selected locations of the fins. Inverse analysis of this study can refer to Ref. [10]. In order to avoid repetition, a detailed procedure is not shown in this manuscript. The computation process is repeated until $\left|\left(T_{j}^{\text {mea }}-T_{j}^{\text {inv }}\right) / T_{j}^{\text {mea }}\right|$ for $j=1,2, \ldots, N$ is less than $10^{-6} . T_{j}^{\text {mea }}$ and $\mathrm{T}_{\mathrm{j}}^{\mathrm{cal}}$ are the experimental temperature data and the fin temperature obtained by Eq. (6) at the $j$-th measurement location, respectively. The heat transfer rate dissipated from the $j$ th sub-fin region $\mathrm{Q}_{j}$, average heat transfer coefficient on the fins $\bar{\hbar}$, heat transfer coefficient based on the fin base temperature $\bar{h}_{b}$ and total heat transfer rate dissipated from the plate fin to the ambient $\mathrm{Q}$ can be expressed as

$$
\begin{gathered}
Q=2 \bar{h}_{j} \int_{A_{j}}\left(T-T_{c}\right) d A \quad \text { for } \mathrm{j}=1,2, \mathrm{~N} \\
\overline{\mathrm{h}} \approx \sum_{\mathrm{j}=1}^{\mathrm{N}} \overline{\mathrm{h}}_{\mathrm{j}} \mathrm{A}_{\mathrm{j}} / \mathrm{A}_{\mathrm{f}}
\end{gathered}
$$

and

$$
\mathrm{Q}=\sum_{\mathrm{j}=1}^{\mathrm{N}} \mathrm{Q}_{\mathrm{j}}=2 \mathrm{~A}_{\mathrm{f}} \overline{\mathrm{h}}_{\mathrm{b}}\left(\mathrm{T}_{0}-\mathrm{T}_{\mathrm{c}}\right)
$$

where the lateral surface area of the fin $\mathrm{A}_{\mathrm{f}}$ is defined as $\mathrm{A}_{\mathrm{f}}=$ 2LH. $A_{j}$ is the lateral surface area of of the $j$-th sub-fin region. Once $\bar{h}_{j}$ values are determined, $Q_{j}, \hbar_{,}, \bar{h}_{b}$ and $Q$ can be obtained from Eqs. (8) and (9).

\section{Three-dimensional Numerical Analysis}

Another major objective of this study is to use FLUENT along with the appropriate flow model to determine the heat transfer and fluid flow characteristics of the present problem. FLUENT along with laminar flow, zero-equation turbulence, $\mathrm{k}-\varepsilon$ turbulence and RNG k- $\varepsilon$ turbulence models is used to obtain numerical results of this study. The results obtained show that the zero-equation turbulence model can be the best one for this problem than other flow models. Thus, FLUENT along with zero-equation turbulence model is used to obtain air velocity and temperature distributions within the rectangular enclosure. Under the assumptions of the steady-state and constant thermal properties, the three-dimensional (3-D) heat conduction equation for the thin fin is expressed as

$$
\frac{\partial^{2} \mathrm{~T}}{\partial \mathrm{x}_{\mathrm{i}}^{2}}=0 \text { for } 0<\mathrm{x}<\mathrm{L}, 0<\mathrm{y}<\mathrm{H}, 0<\mathrm{z}<\mathrm{t} / 2
$$

The boundary conditions at $\mathrm{z}=0$ and $\mathrm{z}=\mathrm{t} / 2$ can be expressed as

$$
-k_{f} \frac{\partial T}{\partial z}=h\left(T-T_{C}\right) \quad \text { at } \quad \mathrm{z}=\mathrm{t} / 2
$$

and

$$
\frac{\partial T}{\partial z}=0 \quad \text { at } \quad \mathrm{z}=0
$$

where $\mathrm{x}, \mathrm{y}$ and $\mathrm{z}$ are the Cartesian coordinates.

The continuity, momentum and energy equations can be expressed in tensor form as

$$
\begin{gathered}
\frac{\partial u_{i}}{\partial x_{i}}=0 \\
u_{j} \frac{\partial u_{i}}{\partial x_{j}}=-\frac{1}{\rho} \frac{\partial p}{\partial x_{j}}+v_{\text {eff }} \frac{\partial^{2} u_{i}}{\partial x_{j}^{2}}+g_{j} \beta \delta_{j 2}\left(T_{a}-T_{\infty}\right)
\end{gathered}
$$

and

$$
c_{p} u_{j} \frac{\partial T_{a}}{\partial x_{j}}=\frac{k_{a}}{\rho} \frac{\partial^{2} T_{a}}{\partial x_{j}^{2}}
$$

where $x_{i}, i=1,2,3$, respectively indicate $x, y$ and $z . u_{i}, p, g_{j}$ and $T_{a}$ are the component of velocity, pressure, acceleration of gravity in the $\mathrm{x}_{\mathrm{j}}$ direction and the air temperature, respectively. $T_{c}$ denotes the average of four temperature measurements on the top surface of the enclosure. $\beta$ is the volumetric thermal expansion coefficient. $\delta_{\mathrm{j} 2}$ is the Kronecker delta. $\rho, v_{\text {eff }}, c_{p}$ and $k_{a}$ are, respectively, the density, effective kinematic viscosity, specific heat and thermal conductivity of the air. They are all assumed to be constant. Parameters $v_{\text {eff }}$ and $k_{a}$ are defined as $v_{\text {eff }}=v_{t}+v$ and $\mathrm{k}_{\mathrm{a}}=\rho v_{\mathrm{t}} \mathrm{c}_{\mathrm{p}} / \mathrm{Pr}_{\mathrm{t}} . v$ and $v_{\mathrm{t}}$ are the laminar and turbulent kinematic viscosities, respectively. The turbulent Prandtl number $\operatorname{Pr}_{t}$ is given as $\operatorname{Pr}_{t}=0.9$ when the air flows on a plane wall surface. The turbulent kinematic viscosity $v_{t}$ is defined as

$$
v_{\mathrm{t}}=\rho \ell_{\mathrm{m}}{ }^{2} \mathrm{~S}
$$

where the mixing length $\ell_{\mathrm{m}}$ and $\mathrm{S}$ are defined as $\ell_{\mathrm{m}}=$ $\min (0.419 \mathrm{~d}, 0.09 \mathrm{~W})$ and $\mathrm{S}=2^{1 / 2} \mathrm{~S}_{\mathrm{ij}}$. $\mathrm{d}$ is the distance from the wall. $\mathrm{W}$ is the distance from the maximum computational domain. The mean strain rate tensor $S_{i j}$ is defined as $\mathrm{S}_{\mathrm{ij}}=\left(\partial \mathrm{u}_{\mathrm{i}} / \partial \mathrm{x}_{\mathrm{j}}+\partial \mathrm{u}_{\mathrm{j}} / \partial \mathrm{x}_{\mathrm{i}}\right) / 2$.

\section{Boundary Conditions}

No-slip conditions are specified at the solid surface. Other walls are insulated. The matching condition of the temperature and heat flux at the fin-fluid interface can be 
written as:

$$
\mathrm{T}=\mathrm{T}_{\mathrm{a}} \text { and } \mathrm{k} \frac{\partial \mathrm{T}}{\partial \mathrm{z}}=\mathrm{k}_{\mathrm{a}} \frac{\partial \mathrm{T}_{\mathrm{a}}}{\partial \mathrm{z}}
$$

\section{Experimental Apparatus}

This experiment is carried out in a rectangular enclosure with $0.03 \mathrm{~m} \times 0.03 \mathrm{~m}$ openings. The length, width and height of the rectangular enclosure are $\mathrm{L}_{\mathrm{e}}=0.06 \mathrm{~m}, \mathrm{~W}_{\mathrm{e}}=0.06 \mathrm{~m}$ and $\mathrm{H}_{\mathrm{e}}=0.08 \mathrm{~m}$, respectively. The test fins with $0.1 \mathrm{~m}$ long, $0.04 \mathrm{~m}$ high and $0.001 \mathrm{~m}$ thick is made of stainless material AISI 304. The fin temperature at the selected measurement locations, $T_{\infty}$ and $T_{0}$ are measured using the T-type thermocouple from this experiment. The limit of its error is $\pm 0.4 \%$ for $0^{\circ} \mathrm{C} \leq \mathrm{T} \leq 350^{\circ} \mathrm{C}$. The schematic diagram of three parallel rectangular fins mounted on the upper surface of the horizontal heating plate is shown in Fig. 2. In order to heat three parallel fins, a square heater with $0.08 \mathrm{~m}$ in length is fixed on the bottom of this plate using the adhesive tapes (Nitto Denko Co., Ltd). The test fins and horizontal plate enclosed with an insulation material are heated to about 7600 seconds using 40W heater. Four thermocouples placed in the gap between the fins and the horizontal plate are fixed to $(\mathrm{L} / 5,0),(2 \mathrm{~L} / 5,0),(3 \mathrm{~L} / 5,0)$ and $(4 \mathrm{~L} / 5,0)$. The average of the four measured temperatures is taken as the fin base temperature $T_{0}$. Contact thermal resistance between the fin and the horizontal plate is assumed to be negligible. The ambient air temperature $T_{\infty}$ is measured at $0.3 \mathrm{~m}$ above the fins.

\section{Results and Discussion}

All physical properties are evaluated at the average of $\mathrm{T}_{0}$ and $\mathrm{T}_{\mathrm{c}}$. The clearance parameter $\mathrm{C}_{\mathrm{f}}$ is defined as $\mathrm{C}_{\mathrm{f}}=$ $\left(\mathrm{H}_{\mathrm{e}}-\mathrm{H}_{\mathrm{f}}\right) / \mathrm{H}_{\mathrm{e}}$. All computations are performed with $\mathrm{L}_{\mathrm{e}}=0.6 \mathrm{~m}$, $\mathrm{fp}=0.01 \mathrm{~m}, \mathrm{H}_{\mathrm{e}}=0.08 \mathrm{~m}, \mathrm{H}_{\mathrm{f}}=0.04 \mathrm{~m}, \mathrm{C}_{\mathrm{f}}=1, \mathrm{t}=0.001 \mathrm{~m}$, $\mathrm{L}=0.1 \mathrm{~m}, \mathrm{k}_{\mathrm{f}}=14.9 \mathrm{~W} / \mathrm{m} \cdot \mathrm{K}$ and extracted speed outside opening $\mathrm{V}_{\mathrm{o}}=1.0 \mathrm{~m} / \mathrm{s}$. The emissivity of the fin measured using FT-IR spectrum 100 (Perkin Elmer Corp., Ltd) is 0.15. $\mathrm{N}_{\mathrm{x}}=21$ and $\mathrm{N}_{\mathrm{y}}=17$ are performed for the inverse method and commercial software FLUENT. The number of grid points in the $z$ direction of the fin is taken from 3-5. The number of grid points between the two fins is taken as 21 and 9 in the $\mathrm{x}$ and $\mathrm{y}$ directions and 8 in the $\mathrm{z}$ direction. A coarser mesh is used in the remainder of this region to save computing time. The number of grid points outside the fins is taken as 76 in both the $\mathrm{x}$ and $\mathrm{z}$ directions and 8 in the $\mathrm{y}$ direction. 241,173 grid points are used to discretize the entire computational domain. The commercial package FLUENT [12] is applied to determine the fluid flow and heat transfer characteristics between the two fins of the plate-fin heat sinks. Unstructured grid system comprising a non-uniform distribution of grid points is used to determine all the numerical results. High density grid points between the two fins and coarse grid points in the remainder of the fins are used. The initial guess of the unknown heat transfer coefficients $\bar{h}_{\mathrm{j}}$ is taken as unity for the inverse method. The rectangular fin is divided into eight regions, i.e., $\mathrm{N}=8$. Eight thermocouples are fixed at the selected measurement locations on the fin, as shown in Fig. 2. $\mathrm{T}_{\mathrm{j}}^{\text {num }}$ denotes the fin temperature obtained by FLUENT [12] at the $j$-th measurement location.

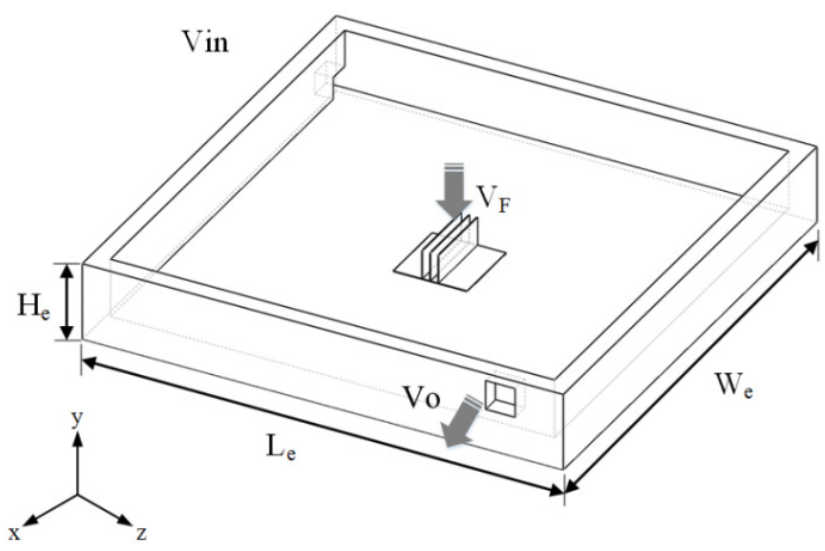

Figure 1. The physical geometry of this problem.

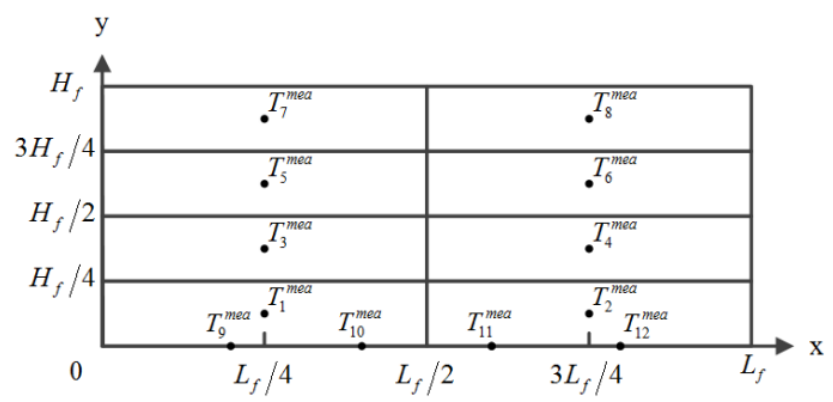

Figure 2. Physical geometry of the measurement locations and sub-fin regions

From Refs. [13, 14], more accurate results can be obtained by a suitable flow model, if the resulting heat transfer coefficient is close to the inverse result and matches existing correlations. Meanwhile, the fin temperature obtained coincides with the experimental temperature data at the selected measurement locations. A comparison of $\mathrm{T}_{\mathrm{j}}$, $\hbar$ and $\hbar^{\text {iso }}$ is shown in Table 1 for various values of downward velocity $V_{F}$ with $C_{f}=1$. It is seen that $\hbar$ and $\hbar^{\text {iso }}$ values obtained by FLUENT along with zero-equation turbulence model are in good agreement with the inverse results. The resulting fin temperature at selected measurement locations also agrees with the experimental data. Thus, the zero-equation turbulence model is suitable for this problem. The present results have good accuracy and reliability. It is worth mentioning that the appropriate grid points may need to be carefully chosen. Due to the action of the extracted speed at the upper opening, the air heated by the heat sink can be extracted from its side, and the cold air is sucked from the bottom opening. Thus, the resulting $\bar{h}$ and $\bar{\hbar}_{\mathrm{b}}$ results increase with $V_{\mathrm{F}}$. The $\bar{h}$ result at $\mathrm{V}_{\mathrm{F}}=2 \mathrm{~m} / \mathrm{s}$ is about 1.26 times that at $\mathrm{V}_{\mathrm{F}}=1 \mathrm{~m} / \mathrm{s}$. The $\bar{h}_{\mathrm{b}}$ 
result at $\mathrm{V}_{\mathrm{F}}=2 \mathrm{~m} / \mathrm{s}$ is about 1.45 times that at $\mathrm{V}_{\mathrm{F}}=1 \mathrm{~m} / \mathrm{s}$.

Table 1. Comparison of $T_{j}, \hbar$ and $\hbar_{b}$ for various $V_{F}$ values

\begin{tabular}{|c|c|c|c|c|}
\hline \multicolumn{2}{|c|}{$\mathrm{V}_{\mathrm{F}}(\mathrm{m} / \mathrm{s})$} & 1.0 & 1.5 & 2.0 \\
\hline \multicolumn{2}{|c|}{$\mathrm{T}_{\mathrm{o}}(\mathrm{K})$} & 333.47 & 327.36 & 324.60 \\
\hline \multicolumn{2}{|c|}{$\mathrm{T}_{\mathrm{c}}(\mathrm{K})$} & 304.31 & 302.93 & 303.05 \\
\hline \multirow{8}{*}{\multicolumn{2}{|c|}{$\begin{array}{ll}\mathrm{T}_{1}{ }^{\text {mea }}(\mathrm{K}) \\
\mathrm{T}_{2}{ }^{\text {mea }}(\mathrm{K}) \\
\mathrm{T}_{3}{ }^{\text {mea }}(\mathrm{K}) \\
\mathrm{T}_{4}{ }^{\text {mea }}(\mathrm{K}) \\
\mathrm{T}_{5}{ }^{\text {mea }}(\mathrm{K}) \\
\mathrm{T}_{6}{ }^{\text {mea }}(\mathrm{K}) \\
\mathrm{T}_{7}{ }^{\text {mea }}(\mathrm{K}) \\
\mathrm{T}_{8}{ }^{\text {mea }}(\mathrm{K})\end{array}$}} & 327.73 & 321.35 & 318.96 \\
\hline & & 328.87 & 321.69 & 319.09 \\
\hline & & 320.47 & 315.15 & 313.36 \\
\hline & & 321.22 & 315.84 & 313.75 \\
\hline & & 314.35 & 312.45 & 310.92 \\
\hline & & 315.03 & 312.59 & 310.97 \\
\hline & & 312.07 & 310.44 & 309.09 \\
\hline & & 313.62 & 311.57 & 310.09 \\
\hline \multirow{8}{*}{\multicolumn{2}{|c|}{$\begin{array}{l}\mathrm{T}_{1}{ }^{\text {num }}(\mathrm{K}) \\
\mathrm{T}_{2}{ }^{\text {num }}(\mathrm{K}) \\
\mathrm{T}_{3}{ }^{\text {num }}(\mathrm{K}) \\
\mathrm{T}_{4}{ }^{\text {num }}(\mathrm{K}) \\
\mathrm{T}_{5}{ }^{\text {num }}(\mathrm{K}) \\
\mathrm{T}_{6}{ }^{\text {num }}(\mathrm{K}) \\
\mathrm{T}_{7}{ }^{\text {num }}(\mathrm{K}) \\
\mathrm{T}_{8}{ }^{\text {num }}(\mathrm{K})\end{array}$}} & 327.44 & 321.97 & 319.66 \\
\hline & & 328.25 & 322.49 & 320.01 \\
\hline & & 319.48 & 315.19 & 313.62 \\
\hline & & 320.79 & 315.98 & 314.12 \\
\hline & & 314.89 & 311.46 & 310.41 \\
\hline & & 316.10 & 312.13 & 310.82 \\
\hline & & 312.30 & 309.41 & 308.70 \\
\hline & & 313.34 & 309.95 & 309.00 \\
\hline \multirow{2}{*}{$\begin{array}{c}\hbar \\
\left(\mathrm{W} / \mathrm{m}^{2} \cdot \mathrm{K}\right)\end{array}$} & Inv & 16.47 & 18.74 & 21.11 \\
\hline & Fluent & 17.15 & 19.99 & 21.53 \\
\hline \multirow{2}{*}{$\begin{array}{c}\hbar_{b} \\
\left(W / m^{2} \cdot K\right)\end{array}$} & Inv & 7.31 & 10.74 & 11.76 \\
\hline & Fluent & 8.34 & 10.27 & 10.88 \\
\hline
\end{tabular}

Fig. 3 shows the air temperature contour in the x-z plane at $y=0.015 \mathrm{~m}$ with $\mathrm{V}_{\mathrm{F}}=1.0 \mathrm{~m} / \mathrm{s}$. It is seen that the air temperature in the vicinity of the entrance of the enclosure is lower than that in the vicinity of the heat sink and enclosure outlet. This is expected because the air outlet includes an air heated by the heat sink. Fig. 4 shows the air velocity pattern in the $\mathrm{x}-\mathrm{z}$ plane at $\mathrm{y}=0.015 \mathrm{~m}$ with $\mathrm{V}_{\mathrm{F}}=$ $1.0 \mathrm{~m} / \mathrm{s}$. It is observed from Fig. 4 cooling air is drawn into the enclosure. Hot air between the fins can be withdrawn from the enclosure with fan opening. The center of the opening with the fan is located at $y=0.6 \mathrm{~m}$. Thus, the air velocity in the vicinity of the opening of the fan cannot be observed. This implies that the flow field of the present problem is 3-D.

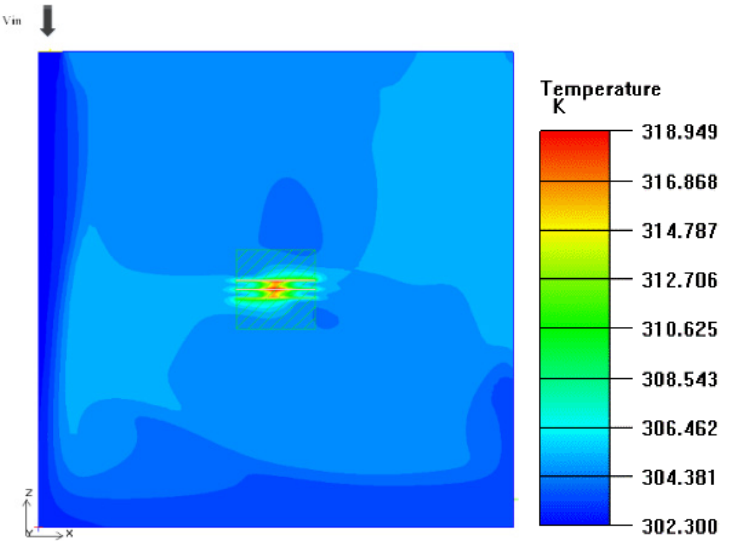

Figure3. Air temperature contour in $\mathrm{x}-\mathrm{z}$ plane at $\mathrm{y}=0.015 \mathrm{~m}$ with $\mathrm{V}_{\mathrm{F}}=1.0$ $\mathrm{m} / \mathrm{s}$.

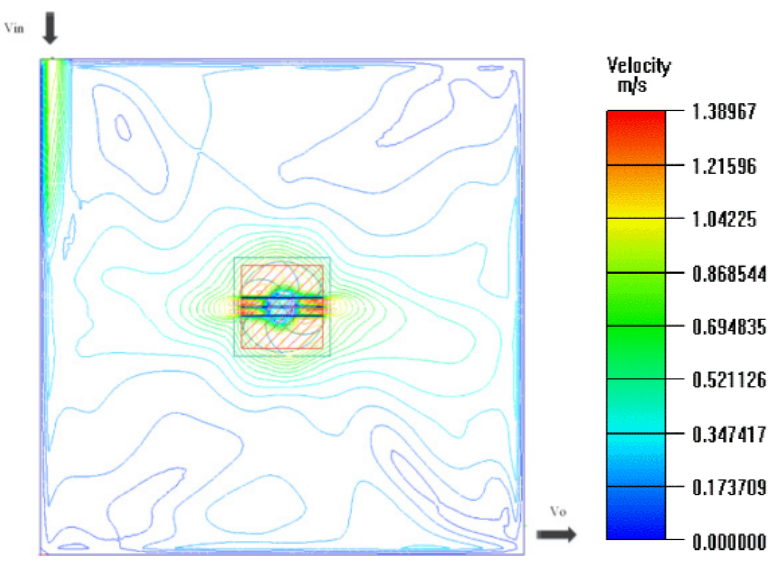

Figure4. Air velocity pattern in $\mathrm{x}-\mathrm{z}$ plane at $\mathrm{y}=0.015 \mathrm{~m}$ with $\mathrm{V}_{\mathrm{F}}=1.0$ $\mathrm{m} / \mathrm{s}$.

\section{Conclusions}

This study uses an inverse method and FLUENT along with the experimental data to determine the fluid flow and heat transfer characteristics for plate-fin heat sink placed in an enclosure with two openings. The results show that $h \square$ and $\bar{h}_{b}$ results obtained by the zero-equation turbulence model are in good agreement with the inverse results. The resulting fin temperature at selected measurement locations also agrees with the experimental data. Thus, the zero-equation turbulence model is suitable for this problem. The present results are reliable. The resulting $\bar{\hbar}$ and $\bar{h}_{b}$ results increase with $\mathrm{V}_{\mathrm{F}}$. In order to determine more accurate numerical results, the appropriate flow model and grid points may need to be carefully chosen. The commercial package FLUENT along with inverse results and experimental data can be applied to obtain more accurate fluid flow and heat transfer characteristics. This study is useful in electronics cooling applications. 


\section{Acknowledgements}

The authors gratefully acknowledge the financial support provided by the National Science Council of the Republic of China under Grant No. NSC 102-2221-E- 006-177-MY3. We would also like to thank Professor Chin-Hsiang Cheng at National Cheng Kung University to give us the commercial software FLUENT.

\section{Nomenclature}

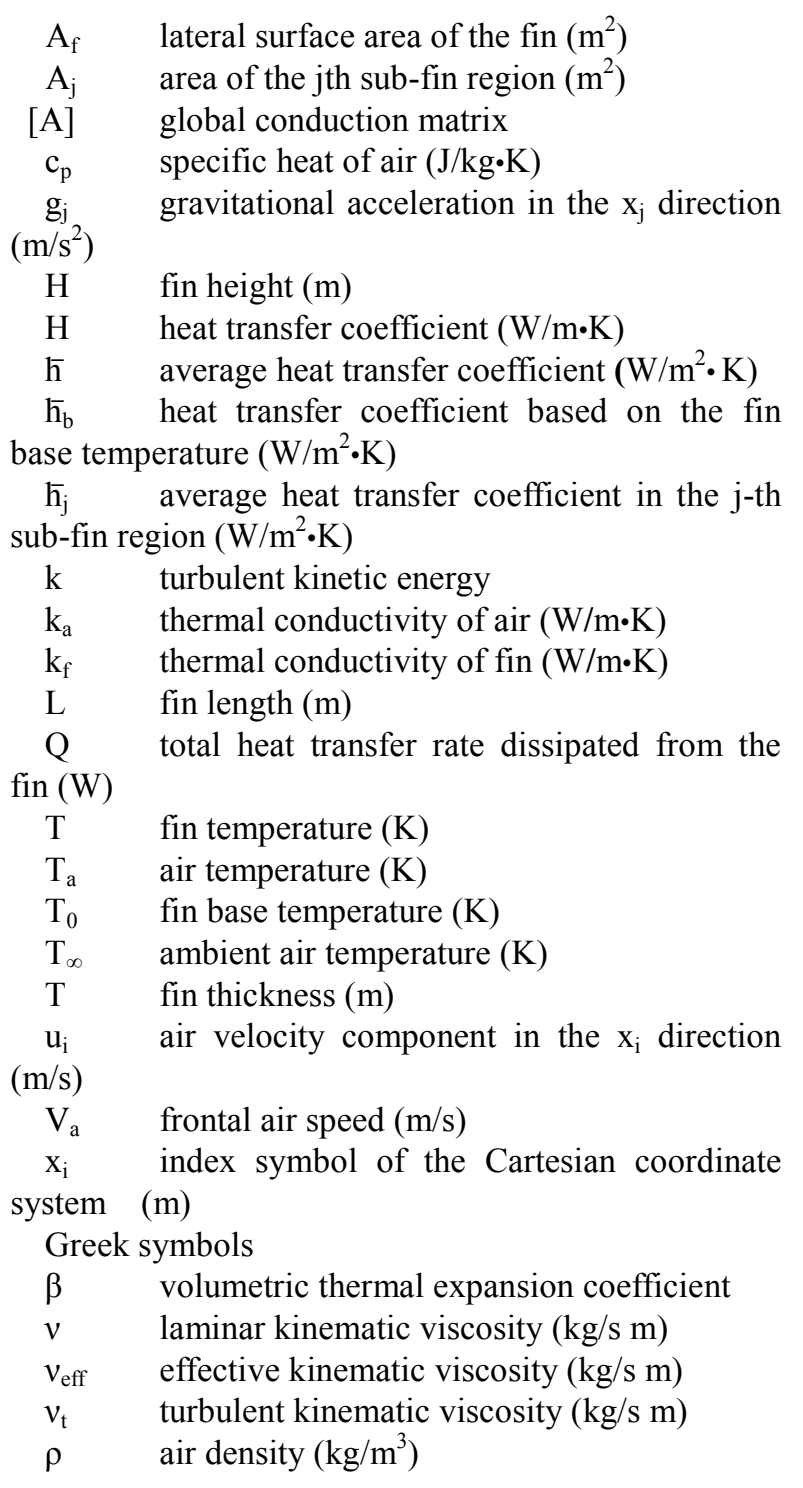

\section{REFERENCES}

[14] H.T. Chen, Y.S. Lin, P.C. Chen, J.R. Chang, Numerical and experimental study of natural convection heat transfer characteristics for vertical plate fin and tube heat exchangers with various tube diameters, Int. J. Heat Mass Transfer 100 (2016) 320-331. 